\title{
Analysis of temperature on the surface of the wrist due to repetitive movements using sensory thermography
}

\author{
C. Camargo ${ }^{a^{*}}$, J. Ordorica ${ }^{a}$, E. J. De la Vega ${ }^{\text {b }, ~ J . ~ E . ~ O l g u i ́ n ~}{ }^{a}$, O. R. López ${ }^{a}$ and J. A. López ${ }^{c}$ \\ ${ }^{a}$ Department of Industrial Engineering, Faculty of Engineering, Architecture and Design, Autonomous University \\ of Baja California, Km. 103 Tijuana-Ensenada highway w/n. Ensenada, Baja California, Mexico. \\ ${ }^{b}$ Division of Graduate Studies and Research, Hermosillo's Institute of Technology, Technological Ave w/n, Her- \\ mosillo, Sonora, Mexico. \\ ${ }^{c}$ Department of Industrial Engineering, Faculty of Chemical Sciences and Engineering, Autonomous University \\ of Baja California, Tijuana, Baja California, Mexico.
}

\begin{abstract}
This study examines changes in body temperature generated in the wrist area through sensory thermography technique because of highly repetitive movements, proving with this technique that there is a decreased ability to perform muscular work, and thereby assess possible pathologies of Cumulative Trauma Disorders (CTDs). Methods: Two healthy right-handed individuals, who performed repetitive work, emulating an operation of the textile industry for three days, generated DTA in the area of the wrist. The evaluation time was of 3 hours 30 minutes in a controlled temperature between 20 and $25^{\circ} \mathrm{C}, 20$ minutes stabilization time at the beginning and end of the operation. Results: The maximum temperatures reached were on the right wrist (RW) of $35.078^{\circ} \mathrm{C}$ over a period of 1 hour 41 minutes 52 seconds; and on the left wrist (LR), $34.663^{\circ} \mathrm{C}$ over a period of 2 hours 42 minutes 51 seconds, detected discomfort in their right shoulder and wrist in the time range which identified the highest temperatures. It was shown that the data does not fit a normal distribution for RW and LW; the data fit the three- parameters Weibull distribution for WR and LW with a correlation coefficient between 0.93 to 0.99.
\end{abstract}

Keywords: hand disorders, work assessment, CTDs, CTS, IR.

\section{Introduction}

Musculoskeletal disorders, including those localized to the upper extremity such as carpal tunnel syndrome (CTS) and forearm tendinitis, are widespread and disabling. They compromised 29 percent of the approximately 1.2 million total workplace illnesses and injuries resulting in lost days from work in 2007 in the United States [1]. In a general European working population [2] found neck/shoulder pain prevalence of approximately $30-50 \%$ and arm pain prevalence of $11-28 \%$.

It has long been known that repetitive motions of he different anatomical structures of the hand and upper extremities can cause injury and disability of one or both limbs. The National Institute of Occupa- tional Safety and Health. Estimates that over $20 \%$ of the labor force involved in jobs of repetitive nature is at risk of developing CTDs [3]. The most common forms of CTDs are: Tendonitis, tenosynovitis, epicondylitis, bursitis, and CTS. The later is disabling condition of the hand (s) that can be caused, precipitated, or aggravated by repetitive motions combined with forceful and/or awkward postures [4-6]. CTS are a specific form of neuropathy in which nerve injury results from compression of neighboring anatomical structures. It occurs up to 10 times with more frequency in women than men, and it is often seen concomitant to hysterectomy, diabetes mellitus, ophorectomy, and pregnancy [7-12].

Although CTDs are believed to occur in a relatively large segment of the population, they generally go

*Corresponding author. Tel: +52 (646)175-0744 E-mail: ccamargo@uabc.edu.mx 
underreported in industry because workers may not associate the symptoms with their jobs, especially when there occur at night after they have left their jobs. In addition, some workers may not report their symptoms for fear of loosing their jobs, or being placed in another area if they complain [13].

Thermography is a noninvasive technique without biologic hazard. It detects, measures, and converts invisible, surface body heat into a visible display, which is then photographed or videotaped as a permanent record. It graphically depicts temperature gradients over a given body surface are at a given time and has been used to study biologic thermoregulatory abnormalities directly or indirectly influencing skin temperature [14].

Infrared thermography (IR) is widely used to display temperature patterns on the surfaces of the skin by taking pictures [15], unlike thermography sensory which bases its operation as its name says in sensors. This technology has its historical basis in the development of underwater digital temperature recorders used to measure the temperature under the water in natural environments, and with potential applications in areas such as oceanography, marine ecology, and industry, among others [16].

The contribution of this paper is to analyze and evaluate the variation in body temperature generated in the wrist area with RW and LW through sensory thermography and potential symptoms, emulating an operation of the textile industry with repetitive motion. Also, prove if the data adjusts to a normal distribution and/or what type of distribution, carrying out tests for normality and distribution adjustments based on the data.

This investigation allowed the making of questions as: What is the behavior of the temperatures of individuals to perform highly repetitive motion over a period of time of 3 hours and 30 minutes? What are the maximum temperatures (Max T) achieved and its symptoms? Do the temperatures show a similarity on the patterns? Data fit a third order polynomial? What type of distribution data stick?

A review of the state of the art research or sensory thermography applications so far not has been found, but the IR which serves as reference for this study.

Changes in body surface heat have interested physicians since the days of Hippocrates [14]. It took another 100 years to develop infrared technology, but in then became a classified World War II priority not to be released until 1960s [17-19]. Therefore it look over 4000 years-from heat estimation by touch when "fingers did the scanning," to sixteenth century thermometry, and then another three centuries before thermometers became a staple of medical practice-to arrive at thermography, today's thermometry of the skin surface [14].

The body's thermal homeostasis and central control of surface temperature is maintained by a hypothalamic regulating center operating through feedback mechanisms [20]. Both sides of the body are affected uniformly and simultaneously; thus, thermal symmetry is the hallmark of normality, whereas skin surface asymmetry strongly suggests abnormality [14].

The skin is one of the body's chief thermoregulators via its large vascular network and associated complex of nerve fibers which together control blood flow within millimeters of the body surface. Superficial perfusion is largely influenced by the sympathetic nervous system. When stimulated by nerve root or peripheral nerve irritation, the sympathetic nervous system causes active vasoconstriction and decreased skin temperature, whereas it greater compromise or complete interruption causes vasodilatation and increased skin temperature. Up to date, the two most commonly used heat detection systems in clinical practice include infrared telethermography and liquid crystal contact thermography [14].

A review of the state of the art research or sensory thermography applications so far have not been found, but only for the IR which serve as reference for this study.

The thermography scan can calculate temperature changes in small parts of the body surface. They illustrated the contribution of the IR in diagnosing and corroborating acute, recurrent and chronic clinical symptoms [14].

A study was published to characterize the effect of exercise (balance for $15 \mathrm{~min}$ ) and responses in the skin temperatures in people with and without carpal tunnel syndrome [21].

It was also published a study characterizing the effect of exercise (on an ergonomics bike) and responses in the skin temperatures due to controlled levels of exercise and temperature conditions [15].

A study was published on the detection of breast cancer by thermography, which has become a powerful tool in conjunction with mammography for diagnostic purposes. Breast cancer is one of the most common diseases among women around the world in these times and is caused by epithelial cells [22].

In recent times, its applications have extended to fields such as engineering and in particular to medicine. It is passive in nature and because of that, will not emit any radiation that could harm the patient or put him in some kind of risk. The ideal 
temperature for making thermal images is between 20 and $25^{\circ} \mathrm{C}$, and as to the percentage of moisture, this must be between $40 \%$ and $60 \%$ [23]

Another study which was aimed to characterize the differences in skin temperatures of between three groups of office workers assessed by dynamic thermography (writing of $9 \mathrm{~min}$ ). Post-typing differences in skin temperature in response to a 9 min typing challenge were detectable through infrared thermography in three groups of office workers: asymptomatic controls, those with distal upper extremity musculoskeletal disorders UEMSDs without cold hands, and those with distal UEMSDs with cold hands [24].

Another study aimed to examine the suitability of using mean dorsal hand skin temperature, before and after a short typing task as an indicator of UEMSD severity. It demostrated a reliable physicologic method of determining UEMSD severity in office workers through the measurement of dorsal hand temperature using IR under a controlled ambient enviroment $\left(18-22^{\circ} \mathrm{C}\right.$ recommended)

A study was published about an analysis of carpal tunnel syndrome developed in the military population of the United States which showed a predominant significance of the group of military women The unadjusted incidence rate of carpal tunnel diagnoses in our population was 3.98 per 1,000 person-years. The adjusted incidence rate ratio for $>=40$-year-old group with the $<20$-year-old-group as the referent category was 11.63 (95\% CI, 10.90, 12.41) [26].

A study was published to estimate the temperature conditions that could cause mental stress, this by immersing both hands in a container of water at a temperature of $3^{\circ} \mathrm{C}$ [27].

In addition, a study was published about a professional swimmer, and reflected the skin temperature analysis, in which temperatures were analyzed with regard to the swimming styles developed in the experiment [28].

A study was published to determine the thermographic changes in temperature associated with the elderly and young people. Which consisted of knee flexion with weight of 1 kilogram added to it during 3 minutes. The results contribute to improve the understanding about temperature changes in elderly people [29]

Note that it is mentioned that for a cumulative trauma disorder can be detected, this must have developed well in advance. It's so that a clinical criteria has limited use in developing a model of prevention, in early detection, and the minimization of days lost due to disability [30].
The contents of this paper are organized as follows: initially presents a general introduction to CTD, IR. Then it shows the formulation of methodological research. Then, critical evaluation is presented, and finally the conclusion, discussion and future research on the topic.

\section{Methodological formulation}

\subsection{Materials}

Materials and equipment used for the development and validation of this research are: a Pentium PC, a $1.2 \mathrm{GHz}$ processor, and $598 \mathrm{MHz}$ in RAM, two Skoll sensory thermographers with a range of $0-40{ }^{\circ} \mathrm{C}$, accuracy $\pm 0.3^{\circ} \mathrm{C}$, resolution of $0.1^{\circ} \mathrm{C}$ [16], an ergonomic chair, a stopwatch, a house heater, a sewing machine, cotton fabrics, micro porous tapes and adhesive tapes. For programming the sensory thermographers, the Akeley program was used. The statistical analysis software is Minitab $\mathbb{R}$ 15 and Microsoft ${ }^{\circledR}$ Office Excel 2007.

\subsection{Methods}

The individuals were asked that before the test to refrain from doing any exercise for a period of 20 minutes [24-25], since previous studies have determined that the estimated period for the temperature of the human body to stabilize (thermalization) is after performing a particular exercise of 20 minutes due to a reduction in the range of body metabolism [31]. On the other hand were also asked to avoid drinking alcohol or smoking previously [25], since smoking causes a decrease in body temperature [32] and drinking alcohol increases it [33].

After the room temperature of the lab was warmed in order to keep it an ideal range of 20 to $25^{\circ} \mathrm{C}$. [34], with the help of a heater to room temperature. After the stabilization period, the individuals were asked to sit in an ergonomic chair and then placed thermographers are sensory in both wrists. Already placed thermographers the subjects were asked to rest their arms on a perfectly flat table at the height of the ribs [34] for a period of 20 minutes.

Then, a highly repetitive operation was emulated as is usually performed in the textile industry for 3 hours and 30 minutes because this period represents the longest working hours of workers which makes these highly repetitive movements. The operation 
involved the movements of reaching, taking, and dropping, among others.

During the test, anomalies or pain were described by the individuals who informed of such pain and in which area was specifically present, to be written down in the log data. Finally, having completed the cycle and after 20 minutes rest, it was proceeded with the withdrawal of the thermographers from the wrists of each individual, and then to the data extraction from the thermographers, and then, do the analysis of results.

Individuals who participated in this research were two individuals in good physical condition. The main anthropometric characteristics of individuals are summarized in Table 1.
It is noteworthy that none of the two individuals (students) had lower back problems or blood pressure problems (high or low) and in parallel none reported problems from addictions to alcohol and / or snuff. Besides none of them had previous experience in developing operations involving repetitive movements in previous works or other long-term motor activity in a workstation.Critical evaluation

The experiment was to carry out section 2 . The results of this experiment are in Table 2. For the analysis of experimental results in this Section 3 presents only the example of the complete analysis for the individual 1 , the day of test 3 , because this presented the highest temperature (specifically the RW).

Table 1

Anthropometric characteristics of individuals

\begin{tabular}{|c|c|c|c|c|c|c|c|}
\hline Individual & Age & Gender & $\begin{array}{c}\text { Weight } \\
(\mathrm{kg})\end{array}$ & $\begin{array}{c}\text { Height } \\
(\mathrm{m})\end{array}$ & $\begin{array}{c}\text { BMI } \\
\left(\mathrm{kg} / \mathrm{m}^{2}\right)\end{array}$ & dominant hand & $\begin{array}{c}\text { Previous } \\
\text { Fractures }\end{array}$ \\
\hline 1 & 23 & Male & 61 & 1.57 & 24.7 & Right & No \\
\hline 2 & 25 & Male & 60 & 1.60 & 23.4 & Right & No \\
\hline
\end{tabular}

Table 2

Temperature Patterns

\begin{tabular}{|c|c|c|c|c|c|c|c|c|c|c|}
\hline $\begin{array}{c}\text { Individual / } \\
\text { Test Day }\end{array}$ & $\begin{array}{c}\text { Max. } \\
\text { Tempera } \\
\text { ture In } \\
\text { RW }\end{array}$ & $\begin{array}{c}\text { Max. } \\
\text { Tempera } \\
\text { ture In } \\
\text { LW }\end{array}$ & $\begin{array}{l}\text { Average } \\
\text { in RW }\end{array}$ & $\begin{array}{l}\text { Average } \\
\text { in LW }\end{array}$ & $\begin{array}{c}\text { Std. } \\
\text { Deviatio } \\
\mathrm{n} \text { in RW }\end{array}$ & $\begin{array}{c}\text { Std. } \\
\text { Deviatio } \\
\mathrm{n} \text { in LW }\end{array}$ & $\begin{array}{l}\mathrm{AD} \text { in } \\
\mathrm{RW}\end{array}$ & $\begin{array}{l}\mathrm{AD} \text { in } \\
\mathrm{LW}\end{array}$ & $\begin{array}{c}\mathrm{R} \\
\text { Adjusted } \\
\text { in RW }\end{array}$ & $\begin{array}{c}\mathrm{R} \\
\text { Adjusted } \\
\text { in LW }\end{array}$ \\
\hline $1 / 1$ & 34.760 & 34.196 & 34.280 & 33.720 & 0.269 & 0.264 & 540.1 & 260.6 & 0.877 & 0.883 \\
\hline $1 / 2$ & 35.062 & 34.663 & 34.070 & 33.700 & 0.889 & 0.842 & 651.5 & 718.3 & 0.884 & 0.927 \\
\hline $1 / 3$ & 35.078 & 34.586 & 32.360 & 32.590 & 1.336 & 1.204 & 141.2 & 110.2 & 0.972 & 0.969 \\
\hline $2 / 1$ & 33.682 & 33.032 & 32.741 & 32.016 & 0.506 & 0.586 & 113.3 & 114.3 & 0.876 & 0.911 \\
\hline $2 / 2$ & 34.154 & 34.276 & 33.254 & 33.271 & 0.695 & 0.654 & 397.7 & 327.0 & 0.868 & 0.805 \\
\hline $2 / 3$ & 33.313 & 33.481 & 32.406 & 32.577 & 0.504 & 0.699 & 379.5 & 399.5 & 0.908 & 0.945 \\
\hline
\end{tabular}

It is noteworthy that none of the two individuals (students) had lower back problems or blood pressure Figures 1 and 2 show that in both cases it was possible to carry out curve fitting of third order to represent the behavior of the temperatures during the experiment. Getting the coefficient $\mathrm{R}^{2}$ of $97.2 \%$ for the RW and $96.9 \%$ for the LW, show that the curve fits obtained with a significance level of $5 \%$ are really good.

In both cases we see that the behavior of temperatures in both wrists were very similar, beginning the ascent during the first hour and a half of work, followed by a decline over the next 2 hours and a possible stabilization of the temperature at the end of them.

The highest temperatures in the test day 3 were $35.078^{\circ} \mathrm{C}$ for the RW and $34.586^{\circ} \mathrm{C}$ for the $\mathrm{LW}$, in a period of 1 hour 41 minutes 52 seconds and 1 hour 40 minutes 06 seconds respectively, we can see that the temperature and times were roughly similar. Since the beginning of the test until the time that the maximum temperatures are achieved, an increase of $5.92^{\circ} \mathrm{C}$ for the $\mathrm{RW}$ and $5.837^{\circ} \mathrm{C}$ for $\mathrm{LW}$ was registered. 


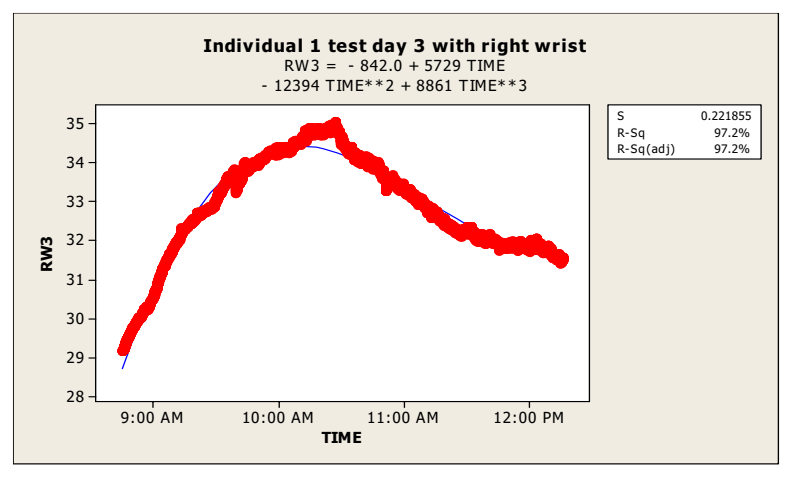

Figure 1. Individual 1 test 1 day 3 with RW

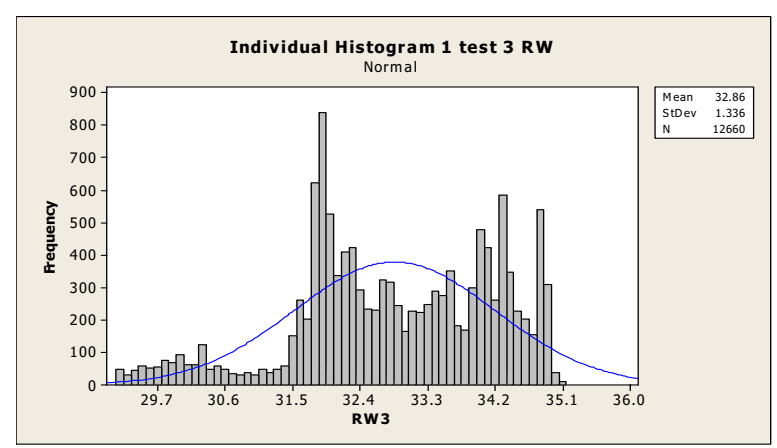

Figure 3. Individual Histogram 1 test 3 RW

LW

Figure 4. Individual Histogram 1 test 3

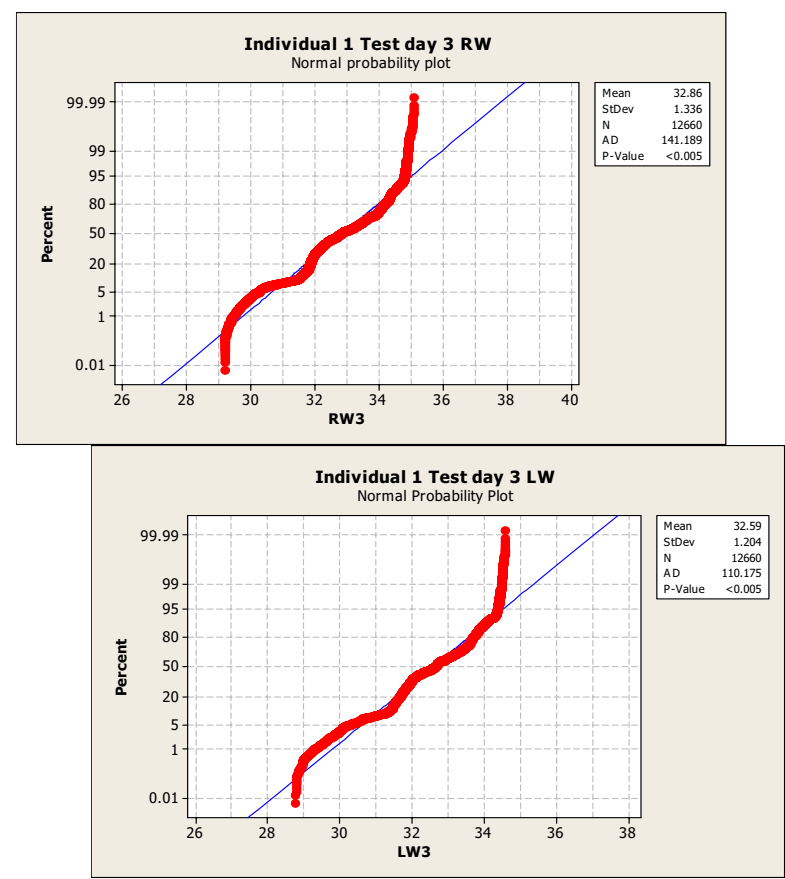

The operator said to feel pain in the right wrist and shoulder approximately two hours after the start of test, also said to feel better and a relief from the pain towards the end of the test, about an hour before the end of it (decline and stabilization).As part of the evidence supporting that the data presented do not follow a normal distribution. Next, Figures 3, 4, 5 and 6 are shown below.

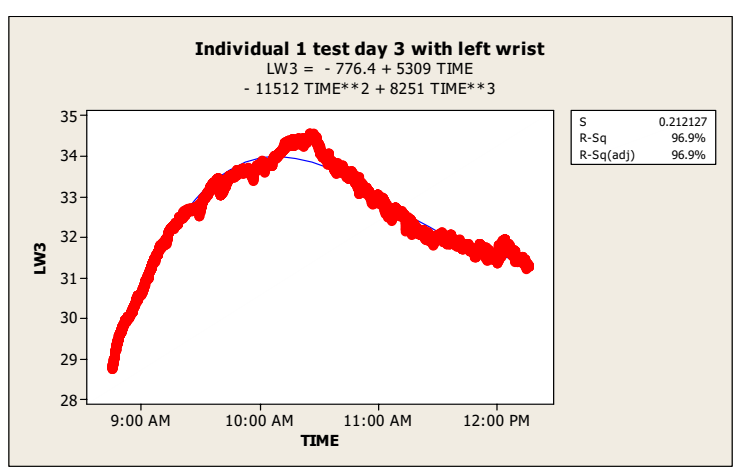

Figure 2. Individual 1 test 1 day 3 with LW

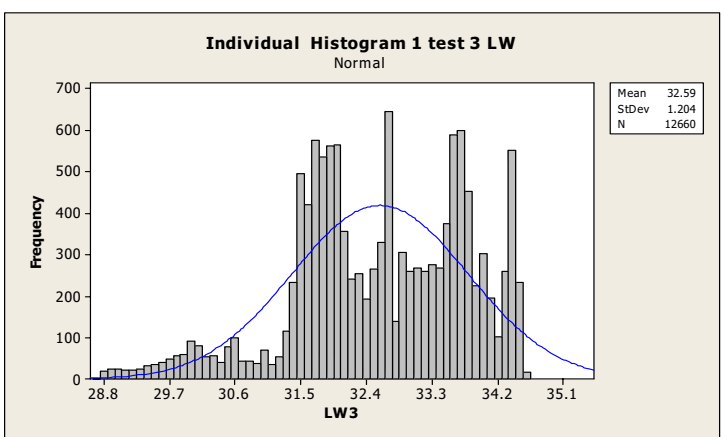


Table 3

Probability distributions of the individual 1 test day 3 RW

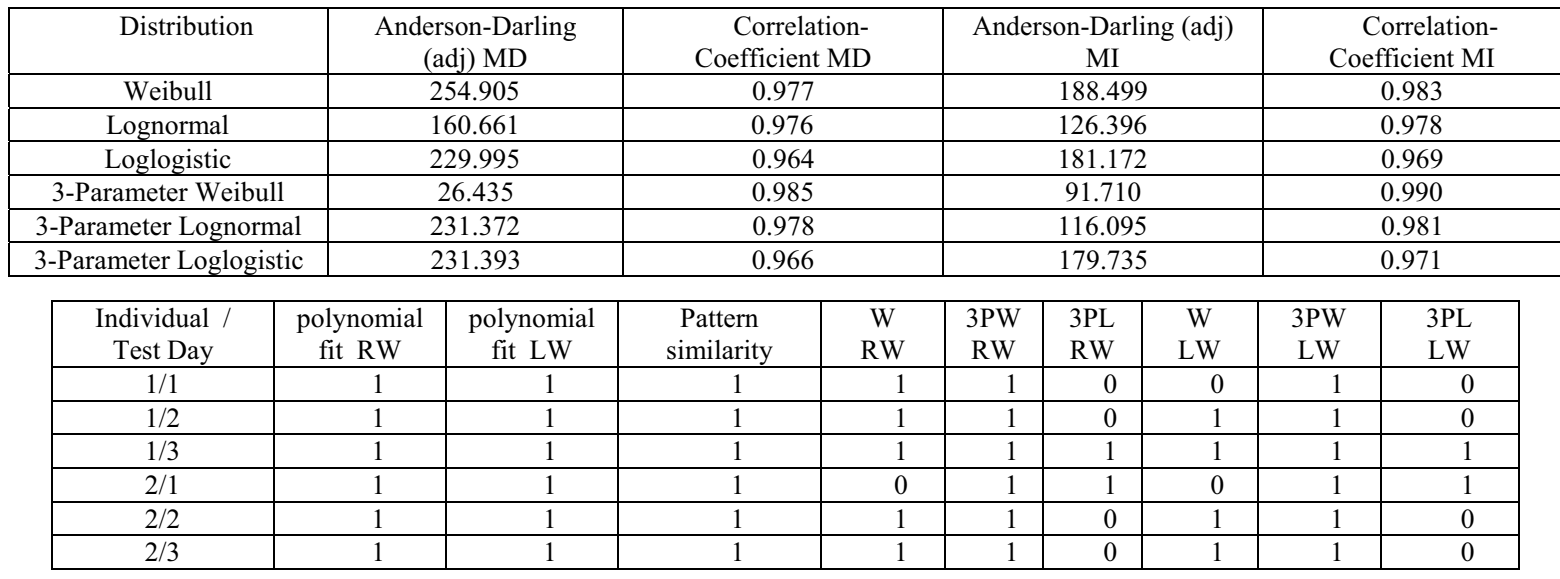

Table 4

Probability distributions and settings for all tests

In Table 3, it was showed that in both wrists was possible to set some kind of probability distribution, which was the 3-parameters Weibull distribution (3PW), the Weibull (W) and 3-parameter lognormal (3PL). In all tests, it was the 3PW distribution the best fit to the data (see Table 4).

In Table 4 shows the summary of the results presented in the tests in three days. This table is approached from a viewpoint in binary code to represent whether or not the polynomial curve fitting of third order, whether there is similarity in the patterns of temperature, and if one or more probability distributions were present to discuss the $\mathrm{LW}$ or RW, as was the case. This is 1 is affirmative and 0 is negative.

\section{Discussion}

This research allowed to answer the questions in Section 1, being the maximum temperatures reached for the individual 1 in $\mathrm{RW} 35.078^{\circ} \mathrm{C}$ over a period of 1 hour and 41 minutes, and 52 seconds (in this test day 3 , explained in detail in section 3 ), and the individual 1 in the $\mathrm{LW} 34.663^{\circ} \mathrm{C}$ in a period of 2 hours and 42 minutes, and 50 seconds (in this test day 2), since the beginning of the test until the time the temperatures maximum is reached and recorded an increase of $2.796^{\circ} \mathrm{C}$, and detected discomfort in the right wrist and shoulder in the time range where the Max. Temperatures were identified.

The maximum temperatures reached for individual 2 were tested for day 2 , RW $34.154^{\circ} \mathrm{C}$ over a period of 2 hours and 28 minutes, and 39 seconds and on the $\mathrm{LW} 34.276^{\circ} \mathrm{C}$ over a period of 2 hours and 28 minutes, and 24 seconds. The highest temperatures were reached at similar times in both wrists. Since the beginning of the test until the time that the maximum temperatures are reached and recorded an increase of $3.44^{\circ} \mathrm{C}$ and $3.67^{\circ} \mathrm{C}$ respectively. Discomfort was detected in the right wrist at 1 hour and 33 minutes, and 30 seconds, and in the right palm when started. Also discomfort was detected in the right shoulder at the time of the highest temperature.

It is concluded that temperatures show a similar pattern (see Table 4), that the data fit a polynomial of third order, and that it gets the type of distribution that would fit more the data, such as the parameters 3 Weibull distribution. It is concluded that, working with sensory thermography provides satisfactory results in the analysis and evaluation on the temperatures of the wrist for the diagnosis or prediction of possible CTDs.

It is concluded that the data does not fit a normal distribution for RW and $\mathrm{LW}$, but the distribution fitted Weibull parameters 3 for RW and LW with a 
correlation coefficient between 0.93 to 0.99 , with a significance level of $5 \%$

Future work is to evaluate a greater number of individuals under the same methodological conditions, including the evaluation of elbow and shoulder. C. Camargo and E. J de la Vega are currently exploring this study. In addition to proposing predictive models for the detection and reduction of CTDs in the workplace.

\section{References}

[1] Bureau of Labor Statistics, U.S. Department of Labor. Nonfatal occupational injuries and illnesses requiring days away from work 2007 (2008), p.p. 08-1716

[2] J. H. Andersen, J. P. Haahr, P. Frost, Risk factors for more severe regional musculoskeletal symptoms: a two-year prospective study of a general working population. Arthritis Rheum 56 (2007), p.p. 1355-1364.

[3] M. Mallory, H. Bradford, An Invisible Work Hazard Gets Harder to Ignore, Business Week (1989), p.p. 92-93.

[4] A. V. Putz, Cumulative Trauma Disorders: A Manual for Musculoskeletal Diseases of the Upper Limbs. Taylor \& Francis. Philadelphia, 1988.

[5] R. C Tanzer, The Carpal-Tunnel Syndrome: A Clinical and Anatomical Study, Journal of Bone and Joint Surgery 41A-.4 (1959), p.p. 626-634

[6] E. R. Tichauer, Some Aspects of Stress on Forearm and Hand in Industry, Journal of Occupational Medicine. 8-2 (1986), p.p. 63-71.

[7] T. J. Armstrong, An Ergonomic Guide to Carpal Tunnel Syndrome, American Industrial Hygiene Association publications, 1983.

[8] P. G. Benson, Dermott, W. Textbook of Medicine 1, fourteenth edition. W.B. Saunders Company 1987.

[9] I. J. Cannon, E. J. Bernacki, W. D.Walden, Personal and Occupational Factors Associated with Carpal Tunnel Syndrome, Journal of Occupational Medicine 23-4 (1981), p.p. 255-258.

[10] L. Hymovich, M. Lindholm, Hand, Wrist and Forearm Injuries. The Result of Repetitive Motions, Journal of Occupational Medicine 8-11 (1966), p.p. 211-228.

[11] G. Phalen, The Carpal Tunnel Syndrome, Journal of Bone and Joint Surgery 1-48A (1966), p.p. 211-288.

[12] G. Phalen, Reflection on 21 years Experience with the Carpal Tunnel Syndrome. JAMA 212-8 (1970), p.p. 1365-1367.

[13] T. J. Armstrong, B. B. Graffon, The Carpal Tunnel Syndrome and Selected Personal Attributes, Journal of Occupational Medicine 21-7 (1979), p.p. 481-486.

[14] F. Feldman, Thermography of the hand and wrist: Practical applications, Hand Clinics 7 (1991), p.p. 99-112.

[15] A. Zontak, S. Sideman, O. Verbitsky, R. Beyar, Dynamic Thermography: Analysis of hand temperature, Annals of Biomedical Engineering 26 (1998), p.p. 998-993.

[16] O. López, Digital submarine thermograph, instrumentation and development 3 (1992), p.p. 92-97.

[17] L. Accairri, L. Cugola, R. Maso, The thermographic hand, Acta thermograph 3 (1978), p.p. 65-75.
[18] H. T. Berthold, Thermography of insensitive limbs, In Abernathy M, Uematsu S: Medical Thermography: Theory and Clinical Aplications. Los Angeles, Brentwood Publishing, (1986), p.p. 69-79.

[19] K. L. Brelsford, S. Uematsu, Thermographic presentation of cutaneous sensory and vasomotor activity in the injured peripheral nerve, J Neurosurg 62 (1985), p.p. 711-715.

[20] AMA Council Report: Thermography in neurological and musculoskeletal conditions. Thermology 2 (1987), p.p. 600607.

[21] S. F. Tchou, J. Costich, C. R. Burguess, K. Lexington, E. C. Wexler, Thermographic observations in Unilateral Carpal tunnel syndrome: Report of 61 cases, The Journal of the hand surgery 17A (1992), p.p. 631-637.

[22] J. M. Dixon, C. McDonald, R. A. Elton, W. R. Miller, Risk of breast cancer in women with palpable breast cysts: a prospective study, Lancet 353 (1999), p.p. 1742-1745

[23] E. Y-K Ng, G.J.L Kaw, "IR scanners as fever monitoring devices: physics, physiology and clinical accuracy". Biomedical Engineering Handbook: CRC Press, Florida 2005, p.p. $1-24$.

[24] J. Gold, M. Cherniack, B. Buchholz, Infrared Thermography for examination of skin temperature in the dorsal hand office workers, Eur J. Apply Physiol 93 (2004), p.p. 245-251.

[25] M.J. Wolf, S. Mountcastle, D.B. Owens, Incidence of carpal tunnel syndrome in the U.S. Military Population, Hand, Ed. Springer New York, 2009.

[26] J. Gold, M. Cherniack, A. Hanlon, T. Dennerlein, J. Dropkin, Skin temperature in dorsal hand of office workers and severity of upper extremity musculoskeletal disorders, Int. Arch. Occup. Envior. Health 82 (2009), p.p. 1281-1292.

[27] K. S. Kim, S. W. Shin, T. H. Yoon, E. J. Kim, J. W. Lee, I Y. Kim, Infrared thermography in human hand, IFMBE Proceedings 14-4 (2006), p.p. 2584-2587.

[28] H. Zaidi, R. TaÏar, S. Fohanno, G. Polidori, The influence of swimming type on the skin-temperature maps of a competitive swimmer from infrared Thermography, Acta of Bioenginnering and Biomechanics 9-1 (2007).

[29] J. J. A. Ferreira, L. C. S. Mendonça, L. A. O. Nunez, A. C. C. Andrade, J. R. Rebelatto, T. F. Salvini, Exercise Associated Thermographic Changes in Young and Elderly Subjects, Annuals of Biomedical Engineering 36 (2008), p. p. 1420-1427.

[30] V. L. Young, M. K. Seaton, C.A. Feely, C. Arfken, D. F. Edwards, C. M. Baum, S. Logan, detecting cumulative trauma disorders in workers performing repetitive tasks, American Journal of Industrial Medicine 27 (1995), p.p. 419431.

[31] E.Y-K. Ng, L.N. Ung, F.C. Ng, L.S.J. Sim, "Statistical analysis of healthy and malignant breast thermography". International Journal of Medical Engineering \& Technology 25 (2001), p.p. $253-263$.

[32] A. A. Puig, Smoking influence in the variations of biochemical, physiological and performance parameters, Barcelona 1993.

[33] http://polaris.unisabana.edu.co/prevencion/adicciones/alcoho 1/alcohol_3.html

[34] E.Y-K Ng, E.C. Kee, Advanced integrated technique in breast cancer Thermography, Journal of Medical Engineering \& Technology 32 (2008), p.p. 103-114 